Article

\title{
Synergistic Effects of Black Phosphorus/Boron Nitride Nanosheets on Enhancing the Flame-Retardant Properties of Waterborne Polyurethane and Its Flame-Retardant Mechanism
}

\author{
Sihao Yin ${ }^{1,2,3}$, Xinlin Ren ${ }^{1,2,3, *}$, Peichao Lian ${ }^{1,2,3}$, Yuanzhi Zhu ${ }^{1,2,3}$ and Yi Mei ${ }^{1,2,3, *(\text { () }}$ \\ 1 Faculty of Chemical Engineering, Kunming University of Science and Technology, Kunming 650500, China; \\ yinsihao1213@126.com (S.Y.); lianpeichao@126.com (P.L.); yuanzhi_zhu@kust.edu.cn (Y.Z.) \\ 2 The Higher Educational Key Laboratory for Phosphorus Chemical Engineering of Yunnan Province, \\ Kunming University of Science and Technology, Kunming 650500, China \\ 3 Yunnan Provincial Key Laboratory of Energy Saving in Phosphorus Chemical Engineering and New \\ Phosphorus Materials, Kunming 650500, China \\ * Correspondence: ren8877@126.com (X.R.); meiyi412@kmust.edu.cn (Y.M.); Tel.: +86-138-8855-1958 (Y.M.)
}

Received: 4 February 2020; Accepted: 2 July 2020; Published: 3 July 2020

\begin{abstract}
We applied black phosphorene (BP) and hexagonal boron nitride (BN) nanosheets as flame retardants to waterborne polyurethane to fabricate a novel black phosphorus/boron nitride/waterborne polyurethane composite material. The results demonstrated that the limiting oxygen index of the flame-retarded waterborne polyurethane composite increased from $21.7 \%$ for pure waterborne polyurethane to $33.8 \%$. The peak heat release rate and total heat release of the waterborne polyurethane composite were significantly reduced by $50.94 \%$ and $23.92 \%$, respectively, at a flame-retardant content of only $0.4 \mathrm{wt} \%$. The superior refractory performances of waterborne polyurethane composite are attributed to the synergistic effect of BP and BN in the gas phase and condensed phase. This study shows that black phosphorus-based nanocomposites have great potential to improve the fire resistance of polymers.
\end{abstract}

Keywords: black phosphorene; boron nitride; flame retardant; waterborne polyurethane

\section{Introduction}

Polymeric materials have been widely used in electronic devices, construction, and transportation. However, most of the polymeric materials have been intrinsically inflammable [1,2]. Therefore, flame-retardant additives are important to mitigate the risk of fire [3,4]. Some halogen-based flame retardants have been banned because they form carcinogens during combustion [5-7]. Compared to traditional halogenated flame retardants, phosphorus-containing flame retardants have attracted much attention due to the advantages of having low smoke and low halogen content as well as being non-toxic [8-10]. Phosphorus flame retardants can be divided into inorganic phosphorus flame retardants and organophosphorus flame retardants. Organophosphorus flame retardants have low cost and good compatibility with polymers, but they have high volatility and poor thermal stability [11]. Inorganic phosphorus flame retardants have high phosphorus content, high flame retardant efficiency and low toxicity, but their particles are usually large, thus resulting in poor compatibility with polymer materials and uneven dispersion [12]. For example, red phosphorus needs to be modified or coated to increase its compatibility with polymer materials [13,14].

Black phosphorus (BP) is a new kind of 2D layered material that is only composed of the phosphorus element [15-17]. Recently, BP has been demonstrated to be a good flame retardant [18-20]. 
The high specific surface area of the layered structure can result in an efficient barrier effect in the process of polymer combustion. Compared with volatile white phosphorus and amorphous red phosphorus, BP also exhibits higher thermal stability and phase-dispersion, which could improve the flame-retardant performance and reduce damage to the mechanical properties of the polymers. In previous research, we reported that BP can effectively enhance the thermal stability and fire resistance of polymers [21]. Yuan $\mathrm{Hu}$, et al. synthesized the BP/carbon nanotube composite and demonstrated its synergistic flame retardant performance for epoxy resin [22]. However, some key indicators of flame-retardant property, such as the limit oxygen index (LOI), for the reported BP-based composite materials need to be further improved.

Hexagonal boron nitride (BN) nanosheet is a widely studied 2D material with high thermal stability, good mechanical strength, and large surface area. It has been found to be a good flame retardant for several polymers [23-25]. Considering the fact that the flame-retardant mechanism of BP materials has been mainly attributed to the formed radicals in the gas phase while the BN nanosheet mainly works in the condensed phase, the combination of BP and BN may have a good synergistic effect to further improve the flame-retardant performance and decrease the additive amount of the flame retardants.

Thus, in this paper, we designed a series of experiments to analyze the synergistic effect and flame-retardant mechanism of BP and BN by filling them into waterborne polyurethane (WPU). Through systematic characterization, we found that adding only $0.4 \mathrm{wt} \% \mathrm{BP} / \mathrm{BN}$ nanosheet could significantly raise the LOI of WPU from $21.7 \%$ to $33.8 \%$. The improvement of flame retardancy involves the combination of the condensed phase and gas phase effects during combustion. In addition, such a small additive amount of BP/BN showed negligible color effect on the WPU (Figure 1), which broadens its real application range.

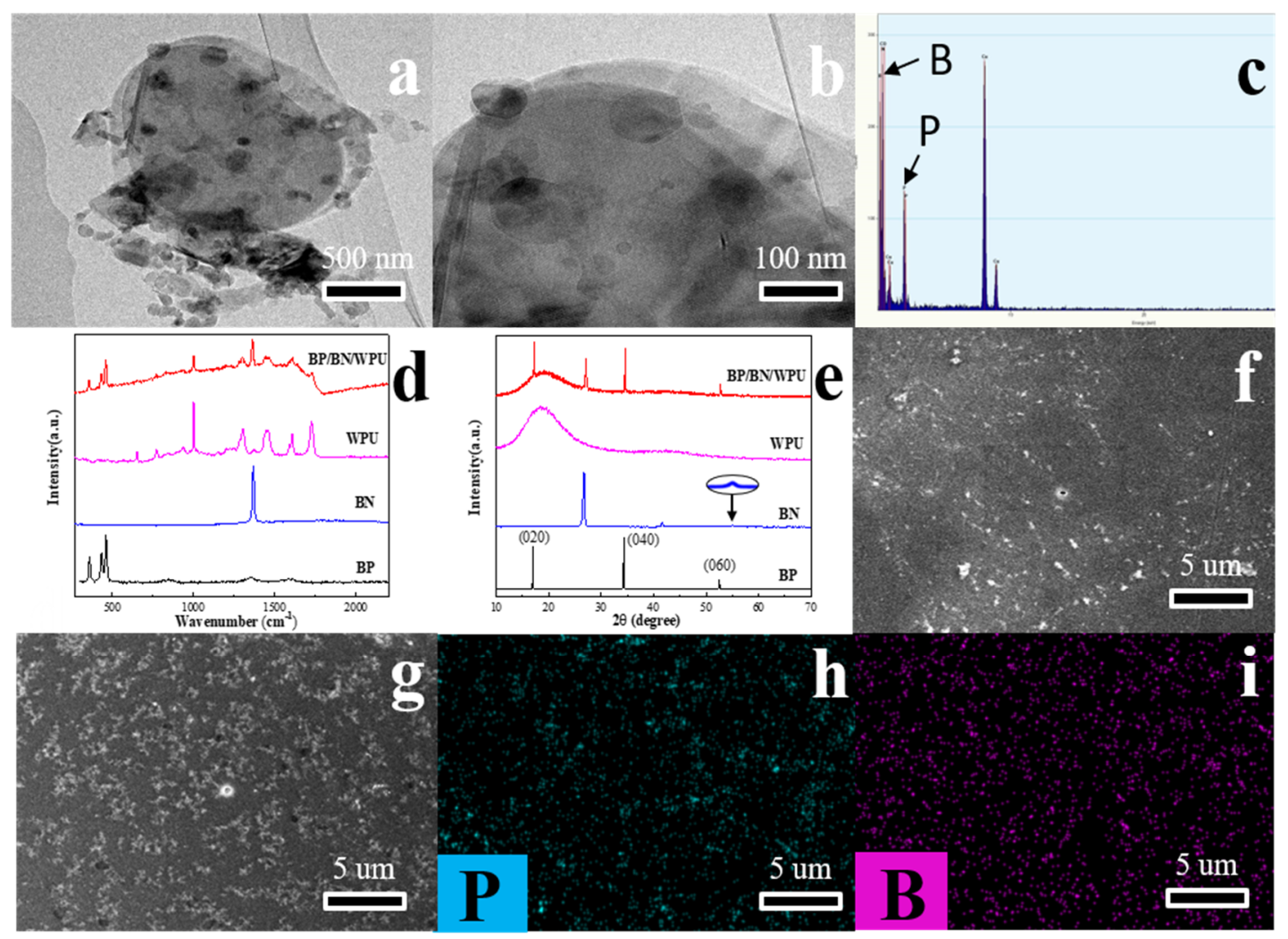

Figure 1. (a,b) TEM image of BP/BN nanosheets; (c) The EDS of BP/BN nanosheets; (d) Raman spectra of BP, BN, WPU and BP/BN/WPU; (e) XRD spectra of BP, BN, WPU and BP/BN/WPU; (f) and (g) SEM image of WPU and BP/BN/WPU; (h) phosphorus mapping in $\mathrm{BP} / \mathrm{BN} / \mathrm{WPU}$ and (i) boron mapping in $\mathrm{BP} / \mathrm{BN} / \mathrm{WPU}$. 


\section{Materials and Methods}

\subsection{Materials}

In this study, BP was prepared by a mineralization transformation method from red phosphorus with the help of iodine and tin in a quartz tube under argon atmosphere. The prepared BP crystals were washed with toluene to remove residual mineralizer, followed by washing with water and acetone. The utilized red phosphorus, iodine, tin, toluene and acetone were analytically pure. The BN was purchased from Shanghai Huayi Group Huayuan Fine Chemicals Co., Ltd., Shanghai, China with a particle size lower than $30 \mu \mathrm{m}$. The WPU latex with a solid content of $25 \mathrm{wt} \%$ was purchased from Anhui Huatai New Material co. Ltd., Hefei, China The water used was deionized water.

\subsection{Fabrication of $B P$ and $B N$ Nanosheets}

$\mathrm{BP}$ was ground for $2 \mathrm{~h}$ into powder, and then $0.5 \mathrm{~g}$ of the powder was added into a conical flask with $500 \mathrm{~mL}$ of deionized water. The conical flask was sealed with argon gas to stop oxidation of the BP. Then the dispersion was added to a working ultrasonic device ( $50 \mathrm{~Hz}, 200 \mathrm{~W}$ ) for $24 \mathrm{~h}$ with the temperature controlled below $30^{\circ} \mathrm{C}$. Afterwards, the dispersed liquid was centrifuged at $3500 \mathrm{rpm}$ for $15 \mathrm{~min}$ by a centrifugal machine (TGL-16C, Shanghai Anting Scientific Instrument Factory, Shanghai, China). Finally, the supernatant liquid was collected and condensed by suction filtration. An argon atmosphere should be used to prevent the oxidation of phosphorene throughout the whole experimental process. The dispersion of boron nitride was also obtained by liquid phase stripping. In order to calculate the concentration of the dispersion, freeze drying was used to remove the moisture. Then the remaining solid was weighed.

\subsection{Preparation of $B P / B N / W P U$ Composite Materials}

The obtained BP and h-BN dispersion were added into a beaker with WPU. After stirring for a few minutes, the beaker was sealed by filling with an argon atmosphere. The mixture was ultrasonicated for $2 \mathrm{~h}$ at low temperature with an ice bath. Then the obtained suspension was poured onto a plate of the size of $120 \times 120 \mathrm{~mm}$ and dried under vacuum at $22{ }^{\circ} \mathrm{C}$. After it was dried completely, the BP/BN/WPU material was formed. The additive amount of $\mathrm{BP} / \mathrm{BN}$ is $0.2 \% / 0.2 \%$. For comparison, the BP/WPU with $0.4 \% \mathrm{BP}$ and $\mathrm{BN} / \mathrm{WPU}$ with $0.4 \% \mathrm{BN}$ were synthesized using the same method (Table 1 ).

Table 1. The additive amount of the $\mathrm{BP}$ and $\mathrm{BN}$ nanosheets in the samples.

\begin{tabular}{cccccc}
\hline Samples & Weight $(\mathrm{g})$ & Percentage of BP (\%) & Percentage of BN (\%) & Content of BP (g) & Content of BN (g) \\
\hline WPU & 22.1 & 0 & 0 & 0 & 0 \\
$0.4 \mathrm{BP} / \mathrm{WPU}$ & 22 & 0.40 & 0 & 0.0880 & 0 \\
$0.4 \mathrm{BN} / \mathrm{WPU}$ & 22.4 & 0 & 0.40 & 0.0444 & 0.0444 \\
$0.2 / 0.2 \mathrm{BP} / \mathrm{BN} / \mathrm{WPU}$ & 22.2 & 0.20 & 0.20 & 0.044 \\
\hline
\end{tabular}

\subsection{Analytical Test}

\subsubsection{Structure Characterizations}

Transmission electron microscopy (TEM, Philips CM100, Amsterdam, The Netherlands) was conducted to observe the $\mathrm{BP}$ and $\mathrm{BN}$ nanosheets at an acceleration voltage of $100 \mathrm{kV}$.

An X-ray diffraction device (XRD, PANalytical Empyrean, Almelo, The Netherlands) was used to analyze the BP, BN powders, as well as the WPU and its composite materials, respectively.

Raman spectra were obtained on a LabRAM-HR Confocal Raman Microprobe (HORIBA Scientific Co., Palaiseau, France) with excitation provided in backscattering geometry by a $633 \mathrm{~nm}$ argon laser line.

Scanning electron microscopy (SEM, Bruker Nano, Bruker, Karlsruhe, Germany) was used to analyze the microstructure of the materials and the charred residue. The WPU and its composite materials with $\mathrm{BP}$ and $\mathrm{BN}$ nanosheets were fractured by liquid nitrogen, then the fracture surfaces 
of the samples were uniformly coated with a layer of gold and then observed by SEM. In order to present the distribution of phosphorene in the polymers, elemental mapping tests were also conducted on another two specimens without a coating of a gold layer. In addition, An EDS test of the charred residue was applied to determine the content of $\mathrm{BP}$ and $\mathrm{BN}$ in the condensed phase.

$\mathrm{X}$-ray photoelectron spectroscopy (XPS) analysis was performed using $\mathrm{Al}$ radiation as a probe (K-alpha, Thermo Fisher Scientific, Waltham, MA, USA) to measure the valence states and chemical composition of the residue of $\mathrm{BP} / \mathrm{BN} / \mathrm{WPU}$.

\subsubsection{Thermal Properties Measurement}

Thermogravimetric analysis (TG) of the materials was performed on a thermal analyzer (NETZSCH STA449F3, NETZSCH, Selb, Germany) with a gas flow rate of $80 \mathrm{~mL} / \mathrm{min}$ under nitrogen atmosphere. The heating rate was $10^{\circ} \mathrm{C} / \mathrm{min}$ and the temperature ranged from $40^{\circ} \mathrm{C}$ to $800^{\circ} \mathrm{C}$.

Thermogravimetric analysis-Fourier transform infrared spectroscopy (TG-FTIR) was performed via a TGA/DSC3 thermogravimetric analyzer (METTLER TOLEDO, Greifensee, Switzerland) linked with a Nicolet FTIR IS50 spectrometer (Thermo Fisher) at a heating rate of $10{ }^{\circ} \mathrm{C} / \mathrm{min}$ within a temperature range of $40^{\circ} \mathrm{C}$ to $800{ }^{\circ} \mathrm{C}$ under a $\mathrm{N}_{2}$ flow of $50 \mathrm{~mL} / \mathrm{min}$. The temperature of the transfer line in the TG-FTIR system was $200^{\circ} \mathrm{C}$.

\subsubsection{Flammability Property Measurement}

The limiting oxygen index (LOI) values were measured according to the standard oxygen index test ASTM D2863-77 by using the device of COI from Motis combustion technology co. LTD (Kunshan, China).

In order to study the combustion behavior, cone calorimetry (CC, PX-07-007, Suzhou phoenix quality inspection instrument co. LTD, Suzhou, China) was performed at a heat flux of $35 \mathrm{~kW} / \mathrm{m}^{2}$. The material specimens were made into a square with the size of $100 \times 100 \times 3 \mathrm{~mm}$. After wrapping in a piece of aluminum film, the specimens were set on fire on the CC.

\section{Results and Discussion}

\subsection{Characterization of $B P / B N / W P U$}

The TEM images reveal the micromorphology of BP and BN nanosheets prepared by liquid phase stripping. As shown in Figure 1a,b, it can be clearly seen that the bulk black phosphorus and $\mathrm{BN}$ were peeled into a few layers of nanoflakes. We suggest that the BP nanosheets are arranged on the BN nanosheets surface, which were fully stripped with clear edges with a length of several micrometers. The Energy Dispersive Spectrometer (EDS) results (Figure 1c) confirmed the elements' distribution in the $\mathrm{BP} / \mathrm{BN}$ nanosheets. Raman spectra and X-ray diffraction (XRD) were carried out for $\mathrm{BP}, \mathrm{BN}$ powder, pure WPU and BP/BN/WPU composite, respectively. As shown in the Raman spectra (Figure 1d), the BP nanosheets show three characteristic peaks of $\mathrm{Ag}_{\mathrm{g}}{ }^{1}, \mathrm{Bg}_{\mathrm{g}}{ }^{2}$, and $\mathrm{Ag}_{\mathrm{g}}{ }^{2}$, corresponding to the crystal orientation [26], thickness [27], and angle [28]. The BN shows the in-plane ring vibration peak of BN (E2g vibration mode) at $1365 \mathrm{~cm}^{-1}$ [29]. The BP/BN/WPU composite shows four new peaks in comparison with pure WPU, indicating the successful introduction of BP and BN nanosheets into the WPU matrix. The XRD spectrum of BP reveals three obvious diffraction peaks (Figure 1e), corresponding to the (020), (040), and (060) plane, respectively [30,31]. The spectrum of BN also has three obvious diffraction peaks, indicating the good crystallinity of BN. The XRD spectrum of $\mathrm{BP} / \mathrm{BN} / \mathrm{WPU}$ retains the main peaks of $\mathrm{BP}$ and $\mathrm{BN}$, which is consistent with the Raman results.

The SEM images of pure WPU (Figure 1f) are observed on the fractured surface. It is shown to be homogeneous and without any additive particles due to the typical fracture behavior of a homogeneous material. Compared with the pure WPU, BP/BN/WPU composite shows several white nanosheets (Figure 1g), which could be attributed to the additives BP and BN. As shown in Figure 1h-i, both the P 
and $\mathrm{B}$ elements distribute uniformly over a large region for the BP/BN/WPU sample. These results indicated that the BP and BN nanosheets were uniformly distributed into the WPU.

\subsection{Thermal Stability of BP/BN/WPU and Its Nanocomposite}

The TG analysis of the specimens was carried out in a $\mathrm{N}_{2}$ atmosphere to analyze the decomposition behavior in a real fire scenario. As shown in Figure 2a, the TG curves of pure BP have an obvious mass loss starting at $420^{\circ} \mathrm{C}$, while the $\mathrm{BN}$ only shows negligible mass loss over the whole temperature range. These results show that the $\mathrm{BP}$ turns into the gas phase after $420^{\circ} \mathrm{C}$, and the $\mathrm{BN}$ is very stable even at higher temperature. From Figure 2b,c, we can see that the WPU shows two major mass loss stages over the selected temperature range. This is caused by the difference in thermal stability between the hard segment and soft segment of WPU. The first mass loss stage is mainly caused by the breakage of urethane bonds in the amine and isocyanate while the second stage is assigned to the decomposition of residual polyols. In contrast to pure WPU, the BP/WPU, BN/WPU and BP/BN/WPU exhibited three main mass loss stages. The third stage of the composite occurred in the range of $440-500{ }^{\circ} \mathrm{C}$, which indicates that the mass loss became slower at this temperature after the addition of $\mathrm{BP}$ and $\mathrm{BN}$ nanosheets. The residue char of $\mathrm{BP} / \mathrm{BN} / \mathrm{WPU}$ reached $10.11 \%$, which is also higher than that of WPU $(0.93 \%), \mathrm{BP} / \mathrm{WPU}(8.11 \%)$, and BN/WPU $(6.44 \%)$. These results revealed that the BP and BN nanosheets can synergistically improve the thermal stability of WPU and promote the formation of residue char [32].
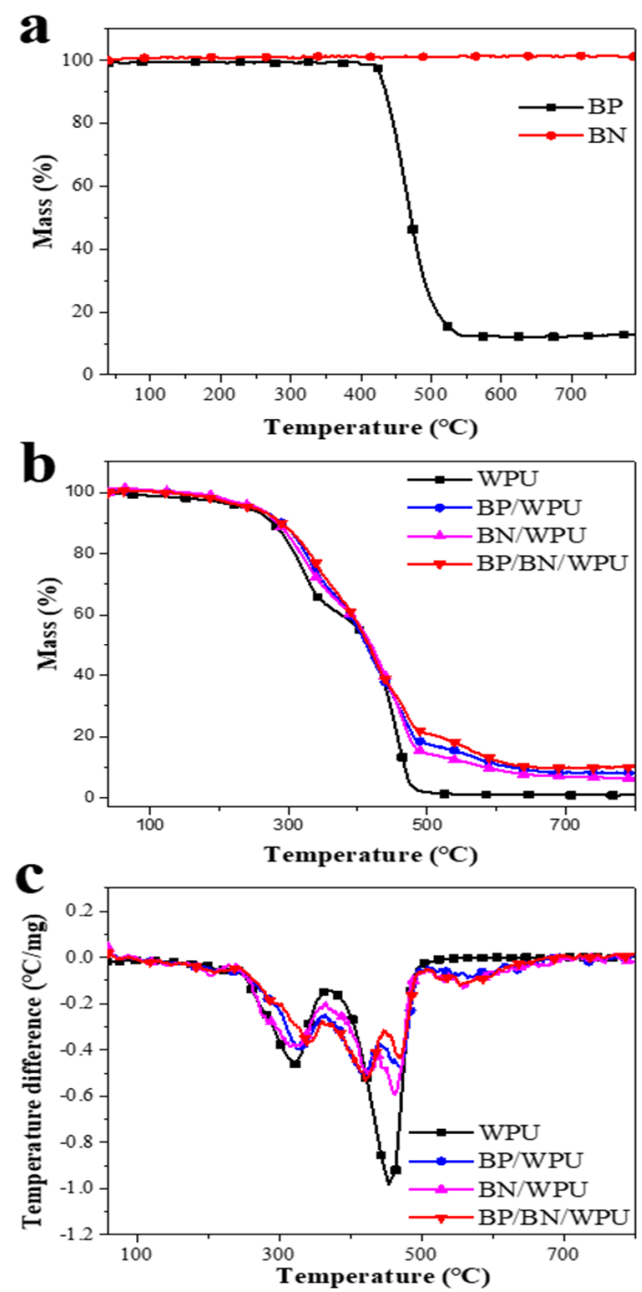

Figure 2. (a) the TGA curves of BP and BN; (b) the TGA curves of WPU, BP/WPU, BN/WPU and $\mathrm{BP} / \mathrm{BN} / \mathrm{WPU}$; and (c) the resulted DTG curves of WPU, BP/WPU, BN/WPU and BP/BN/WPU. 


\subsection{Fire Safety Properties of $B P / B N / W P U$}

The limiting oxygen index (LOI) test is used to determine the flammability of the samples. As depicted in Figure 3, the LOI of pure WPU is $21.8 \%$, indicating that the polymeric matrix is a flammable material. Adding $0.4 \mathrm{wt} \%$ of $\mathrm{BP}$ or $\mathrm{BN}$ increased the LOI to $24.5 \%$ for $0.4 \% \mathrm{BP} / \mathrm{WPU}$ and $26.7 \%$ for $0.4 \% \mathrm{BN} / \mathrm{WPU}$, respectively. Interestingly, simultaneous addition of $0.2 \%$ of $\mathrm{BP}$ and $\mathrm{BN}$ into WPU significantly increase the LOI to $33.8 \%$ and reached the V0 of fire resistance. That is to say, BP and $\mathrm{BN}$ have a synergistic effect in enhancing the self-extinguishing ability of WPU in a real fire scenario.

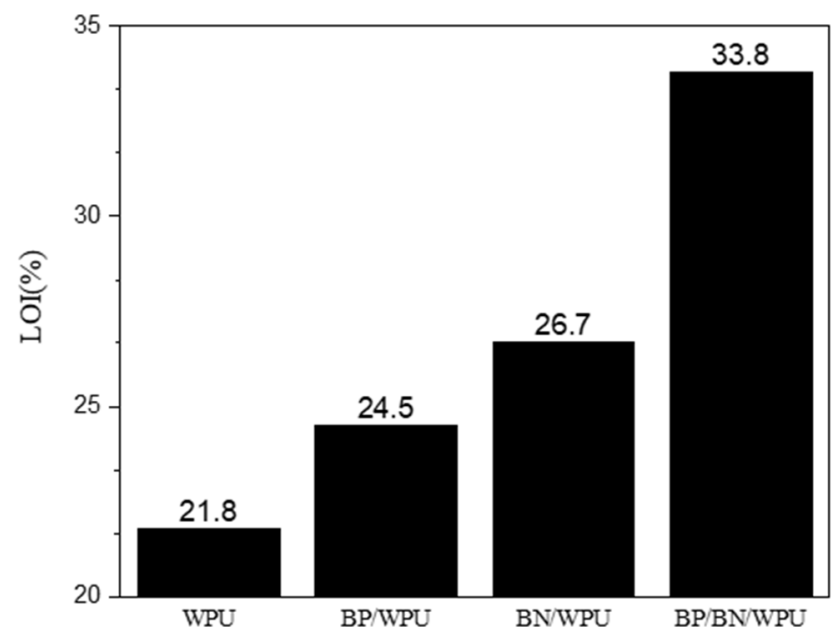

Figure 3. The additive amount of the flame retardant and values of the limit oxygen index (LOI) of the samples.

The cone calorimeter (CC) tests were applied to simulate a real fire scenario. The results are shown in Figure 4 and detailed data are given in Table 2. The total heat release (THR) and the peak of heat release rate (PHRR) of pure WPU are $84.20 \mathrm{MJ} / \mathrm{m}^{2}$ and $452.5 \mathrm{~kW} / \mathrm{m}^{2}$, respectively, indicating that pure WPU released a large amount of heat and made it easy to cause the "flashover" phenomenon. The BP/BN/WPU exhibits the best flame-retardant properties, with a $50.94 \%$ decrease in PHRR (Figure $4 \mathrm{a}$ ) and $23.92 \%$ decrease in THR (Figure $4 \mathrm{~b}$ ), respectively. The introduction of BP and BN nanosheets into WPU significantly reduced heat release and restricted the "flashover" phenomenon. The time to PHRR (TPHRR) and time to ignition (TTI) values of the materials are also shown in Table 2. The TPHRR of BP/BN/WPU arrived last of all. That is to say the burning time of the material was increased, which is a benefit for escaping, rescuing, and firefighting. The TTI of pure WPU and BN/WPU have bigger values than pure BN/WPU and BP/BN/WPU, which indicates that the addition of BP makes the polymer matrix easy to ignite. This phenomenon is a common feature of phosphorus-based flame retardants $[33,34]$. The reason may be that the addition of phosphorus results in the composite polymers having a lower decomposition temperature, leading them to release inflammable gases and ignite earlier. The average of the effective heat of combustion (av-EHC) reveals the volatiles dilution in the gas phase, and usually also discloses the inhibition of gas phase combustion by flame retardants. As shown in Table 2, the av-EHC of WPU and BN/WPU are not much different. This indicates that $\mathrm{BN}$ mainly plays a role in the condensed phase rather than the gas phase. Compared with WPU, the av-EHC of BP/WPU and BP/BN/WPU is much lower. The low av-EHC is due to the capture of gas phase radicals by black phosphorus during combustion.

The $\mathrm{CO}_{2}$ release (Figure 4c) and the $\mathrm{CO}$ release (Figure 4d) curves indicate that $\mathrm{CO}_{2}$ is the main released gas, with little difference in release amount during the burning process. However, the $\mathrm{CO}$ release amount of $\mathrm{BP} / \mathrm{WPU}$ is the highest, and the $\mathrm{CO} / \mathrm{CO}_{2}$ ratio was increased due to added $\mathrm{BP}$, which indicates that $\mathrm{BP}$ works in the gas phase with the ability to restrict the complete combustion of polymer. 

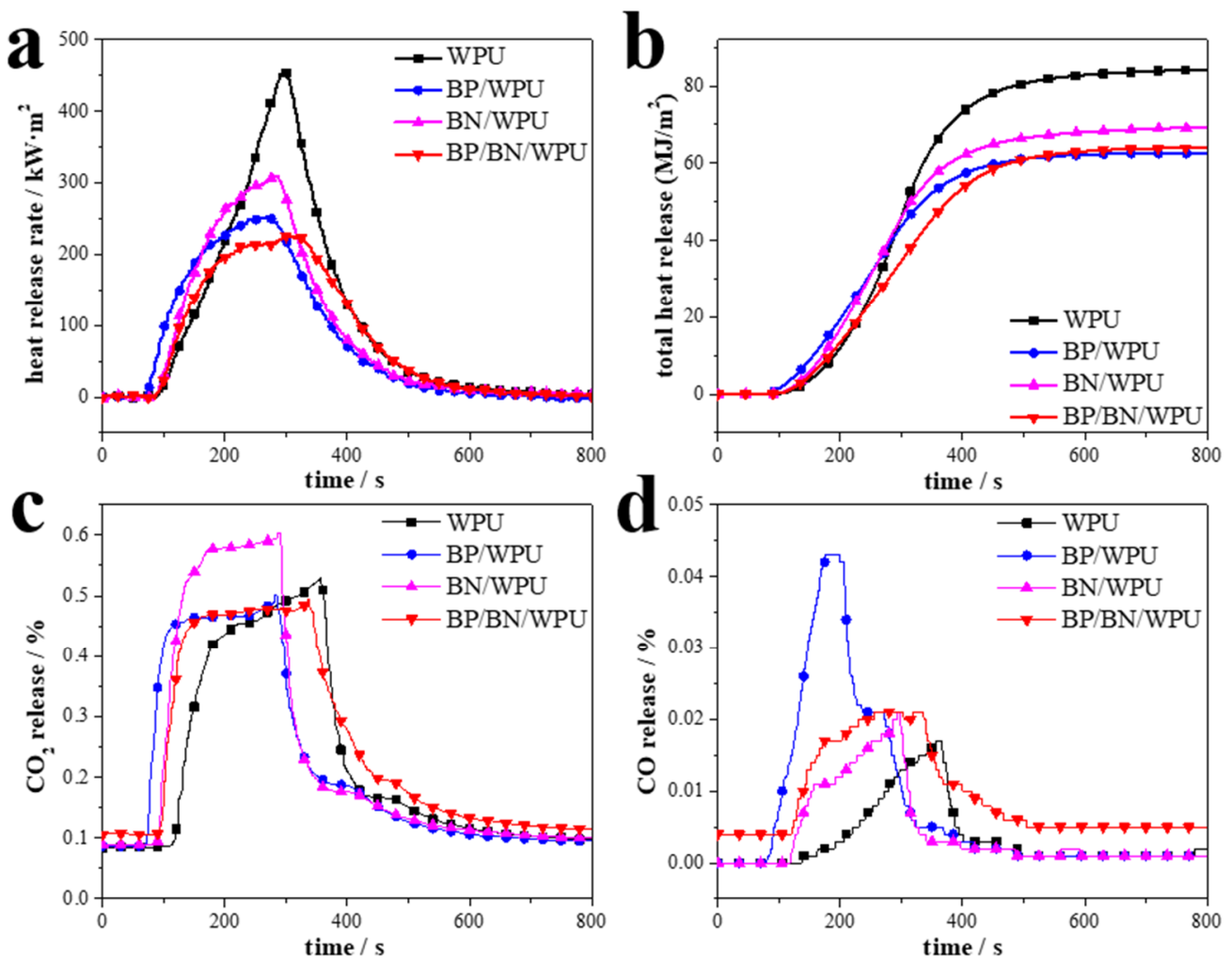

Figure 4. Cone calorimeter test of the samples: (a) HRR curves; (b) THR curves; (c) $\mathrm{CO}_{2}$ release curves; (d) $\mathrm{CO}$ release curves.

Table 2. The cone calorimeter test data of WPU, G/WPU, and BP/G/WPU.

\begin{tabular}{|c|c|c|c|c|c|c|c|c|}
\hline Sample & TTI (s) & TPHRR (s) & $\begin{array}{c}\text { PHRR } \\
\left(\mathrm{kW} / \mathrm{m}^{2}\right)\end{array}$ & $\begin{array}{c}\text { THR } \\
\left(\mathrm{MJ} / \mathrm{m}^{2}\right)\end{array}$ & $\begin{array}{c}\text { Av-EHC } \\
\text { (MJ/kg) }\end{array}$ & $\mathrm{CO} / \mathrm{CO}_{2}$ & EFF & SE \\
\hline WPU & 65 & 297 & 452.5 & 84.20 & 31.07 & 0.021 & & \\
\hline BP/WPU & 40 & 257 & 252.7 & 62.57 & 29.29 & 0.056 & 499.5 & 1.15 \\
\hline BN/WPU & 62 & 264 & 308.3 & 72.25 & 31.30 & 0.027 & 360.5 & 1.5 \\
\hline $\mathrm{BP} / \mathrm{BN} / \mathrm{WPU}$ & 51 & 305 & 222.0 & 64.06 & 27.9 & 0.037 & 576.25 & \\
\hline
\end{tabular}

The flame retardant effectivity (EFF) and synergistic effectivity (SE) are used to numerically evaluate the synergistic effect of multi-component flame retardant systems $[35,36]$. Flame retardant effectivity (EFF) and synergistic effectivity (SE) were calculated from CC data as follows: $E F F=\left(P H R R_{\text {polymer }}\right.$ - $\left.\mathrm{PHRR}_{\text {composite }}\right) /$ Flame-retardant content; $\mathrm{SE}=\mathrm{EFF}_{\text {Flame-retardant }}+$ synergists $/ \mathrm{EFF}_{\text {Flame-retardant }}$. $\mathrm{BP} / \mathrm{BN} / \mathrm{WPU}$ has the highest EEF value, indicating that compared with the single flame retardant, $\mathrm{BP}$ and $\mathrm{BN}$ synergistic flame retardant has the highest flame retardant efficiency. The SE values of $\mathrm{BP} / \mathrm{WPU}$ and $\mathrm{BN} / \mathrm{WPU}$ materials are 1.15 and 1.5, respectively, indicating that $\mathrm{BP}$ and $\mathrm{BN}$ can synergistically improve the flame retardancy of WPU.

\subsection{Flame-Retardant Mechanism of BP/BN/WPU}

\subsubsection{Products Analysis of Carbon Residue}

The residues after the CC tests were used to analyze the products after combustion, and the corresponding results are summarized in Table 3. The SEM images were used to observe the microstructure of the residues (Figure 5). The pure WPU left scarcely any residue (Table 3). Both the addition of BP and BN could enhance the residues of WPU, and the BP/BN/WPU further increase the residues up to $10.34 \%$. This result was also confirmed by the digital images of residues in Figure 5a1-d1. Figure $5 \mathrm{a} 2$ shows the residue of the pure WPU presents a lot of large cracks and $\sim 10 \mu \mathrm{m}$ holes. 
The enlarged image (Figure 5a3) shows that the residue of WPU is shaggy in shape with discontinuous particles. This structure usually facilitates heat transformation and the release of inflammable gas. After the addition of BP and BN, the BP/WPU and BN/WPU show obvious structure difference with relatively smaller holes and smoother surface (Figure 5b3,c3). The residue of BP/BN/WPU exhibited a completely dense surface without small holes, which indicates the good synergistic effect between the $\mathrm{BP}$ and $\mathrm{BN}$ nanosheets in triggering the catalytic carbonization and constructing a barrier.

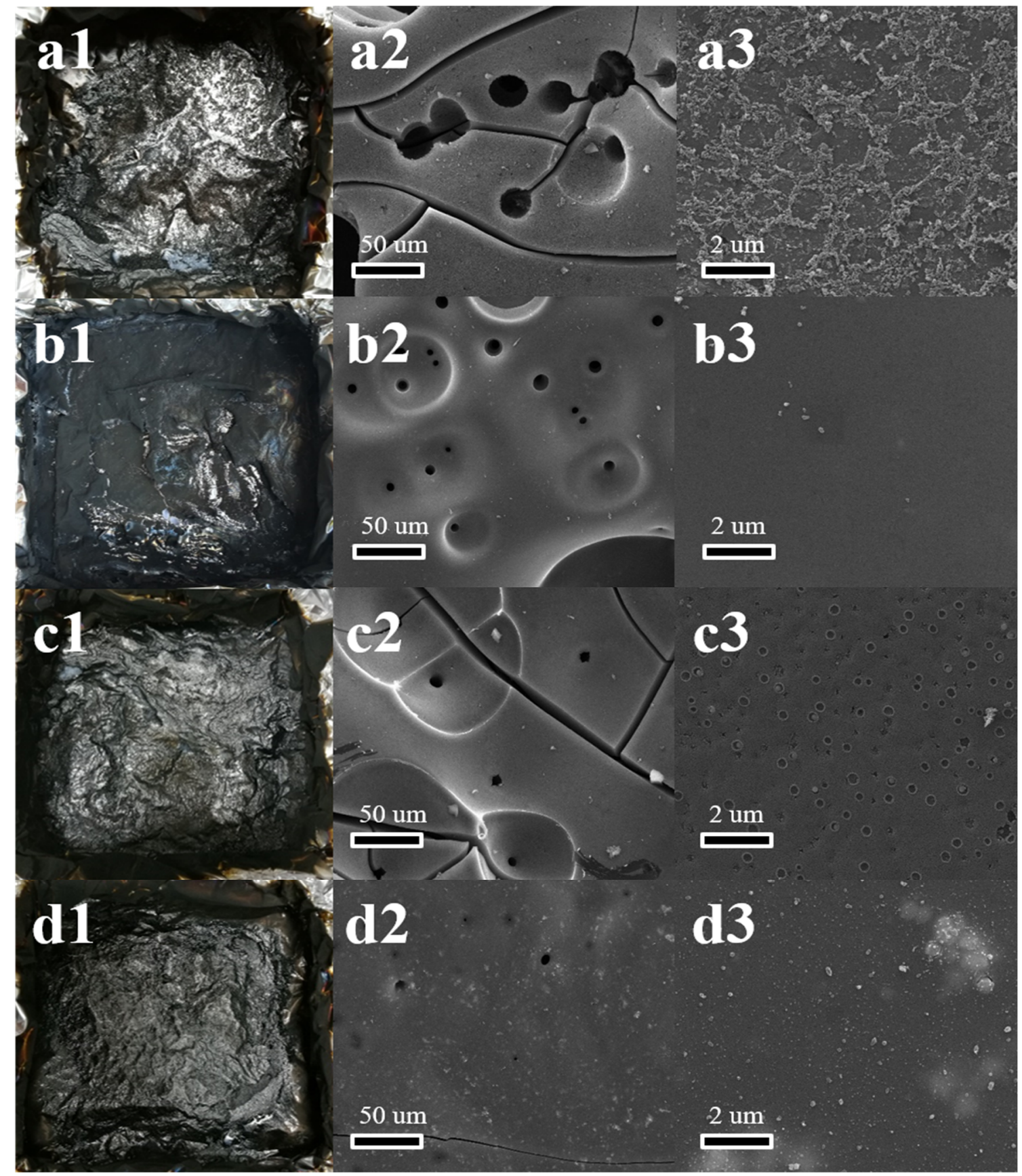

Figure 5. The images of the residues after the CC test: $(\mathbf{a 1}, \mathbf{b 1}, \mathbf{c 1}, \mathbf{d 1})$ the real picture of the pure WPU, $\mathrm{BP} / \mathrm{WPU}, \mathrm{BN} / \mathrm{WPU}, \mathrm{BP} / \mathrm{BN} / \mathrm{WPU}$, respectively; (a2,b2,c2,d2) SEM image of the pure WPU, BP/WPU, $\mathrm{BN} / \mathrm{WPU}, \mathrm{BP} / \mathrm{BN} / \mathrm{WPU}$, respectively; $(\mathbf{a} 3, \mathbf{b} 3, \mathbf{c} 3, \mathbf{d} 3)$ the enlarged SEM image of the pure WPU, BP/WPU, $\mathrm{BN} / \mathrm{WPU}, \mathrm{BP} / \mathrm{BN} / \mathrm{WPU}$. 
Table 3. The content of $\mathrm{BP}$ and $\mathrm{BN}$ nanosheets in the residues after the $\mathrm{CC}$ test.

\begin{tabular}{ccccccc}
\hline Residue Samples & Weight (g) & $\begin{array}{c}\text { Total } \\
\text { Residues (\%) }\end{array}$ & $\begin{array}{c}\text { Condensed } \\
\text { Phase of P (\%) }\end{array}$ & $\begin{array}{c}\text { Condensed } \\
\text { Phase of BN (\%) }\end{array}$ & $\begin{array}{c}\text { Gas Phase } \\
\text { of P (\%) }\end{array}$ & $\begin{array}{c}\text { Gas Phase } \\
\text { of BN (\%) }\end{array}$ \\
\hline WPU & 0.20 & 0.1 & 0 & 0 & 0 & 0 \\
0.4\%BP/WPU & 1.3 & 6.34 & 9.75 & 0 & 90.25 & 0 \\
$0.4 \%$ BN/WPU & 2.1 & 7.38 & 0 & 66.96 & 0 & 33.04 \\
$0.2 \% / 0.2 \%$ BP/BN/WPU & 2.4 & 10.34 & 19.46 & 68.69 & 80.54 & 31.31 \\
\hline
\end{tabular}

EDS analysis was carried out to confirm the different roles of $\mathrm{BP}$ and $\mathrm{BN}$ in the flame retardant. As shown in Table 3, the element $P$ content in the residue of BP/WPU was only 0.0086 g, indicating that $90.25 \%$ of $\mathrm{BP}$ is consumed during combustion. The element $\mathrm{B}$ in the residue of BP/BN/WPU was $0.060 \mathrm{~g}$. which means most $\mathrm{BN}$ was retained and functioned in the condensed phase. According to a previous study on the flame retardant properties of phosphorus [37], BP may also play a key role in the gas phase because it can be converted into $\mathrm{P}-\mathrm{O}$ radicals and diffuse in the surrounding gas, which can then react with the $\mathrm{H}$ or $\mathrm{OH}$ radicals generated by polymers under the burning conditions, consequently reducing the energy of the flame. $\mathrm{BN}$ is stable and will accumulate in the condensed phase, which can form a physical barrier to reduce heat transfer and release of combustible gases [38-40].

In order to further analyze the component of BP in the residue after the CC test, XPS was conducted on the residue powder of BP/BN/WPU. The high-resolution P1s XPS of BP/BN/WPU (Figure 6a) can be deconvoluted into three peaks with binding energies at 132.3, 134.0 and $134.8 \mathrm{eV}$, corresponding to $\mathrm{P}-\mathrm{C}$, $\mathrm{P}-\mathrm{O}-\mathrm{C}$ and phosphoric anhydride $\left(\mathrm{P}_{2} \mathrm{O}_{5}\right)$ [41], respectively. Figure $6 \mathrm{~b}$ shows the high-resolution XPS spectra of B 1s, which was deconvoluted into two peaks with binding energies at 190.7 and $192.2 \mathrm{eV}$ corresponding to the $\mathrm{B}-\mathrm{N}, \mathrm{B}-\mathrm{O}-\mathrm{C}$. Boron element mainly exists in $\mathrm{BN}$ form in the residue, and a small amount of B forms chemical bonds with $\mathrm{C}$. This result indicates that BP can be converted into phosphoric acid and phosphoric anhydride at high temperature, which can promote the polymers to produce a carbon layer. In addition, $\mathrm{BN}$ also play a catalytic role in carbon formation. The generated carbon layer and the amount of BN left behind will form an insulating layer to prevent the materials from contacting with oxygen and heat transferring, consequently weakening the fire $[42,43]$.
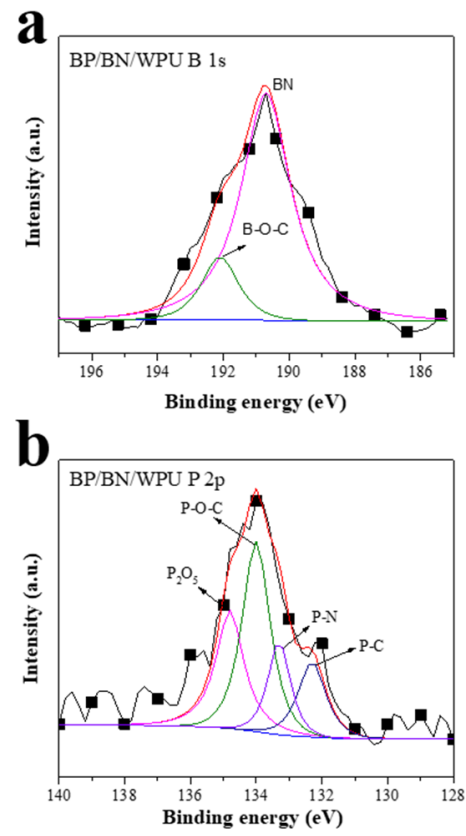

Figure 6. XPS spectra of the residue of BP/BN/WPU composite material after CC test; (a) high-resolution XPS spectra of B 1s of the residue of BP/BN/WPU composite material; (b) high-resolution XPS spectra of $\mathrm{P} 2 \mathrm{p}$ of the residue of $\mathrm{BP} / \mathrm{BN} / \mathrm{WPU}$ composite material. 


\subsubsection{The Product Analysis of the Gas Phase}

In order to determine the pyrolytic mechanism, the decomposition process of BP/BN/WPU was analyzed by Thermogravimetric analysis-Fourier transform infrared spectroscopy (TG-FTIR). The 3D map of the FTIR spectra shows BP/BN/WPU releases $\mathrm{CO}_{2}$ earlier than pure WPU (Figure 7a,b). The results indicated that the addition of $\mathrm{BP} / \mathrm{BN}$ can release non-combustible gas in the initial thermal decomposition of WPU, which can dilute the oxygen from the air and dilute combustible gases from the material.
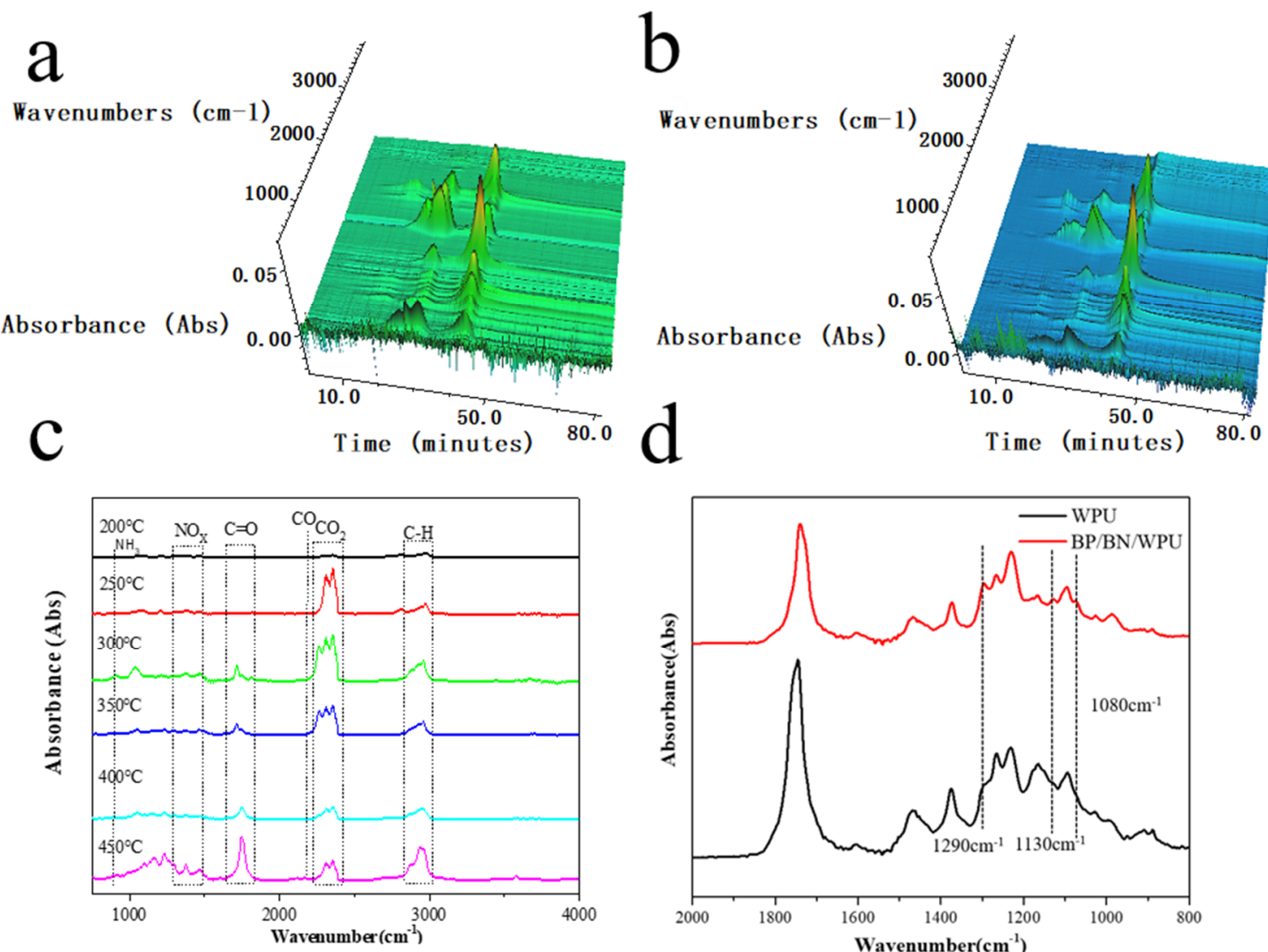

Figure 7. (a) 3D image of FTIR spectra of the WPU; (b) 3D image of FTIR spectra of the BP/BN/WPU; (c) The FTIR spectra of BP/BN/WPU obtained at different temperatures; (d) The enlarged image for comparison of the biggest mass loss in the second TG stages of the pure WPU and BP/BN/WPU.

To further study the thermal degradation process, the chemical structure changes of the $\mathrm{BP} / \mathrm{BN} / \mathrm{WPU}$ at different pyrolysis temperatures were investigated (Figure 7c). The changes in characteristic peaks reflect the detailed decomposition process of WPU and WPU composites. The peak at $2800-3100 \mathrm{~cm}^{-1}$ could be attributed to the stretching vibration of $\mathrm{C}-\mathrm{H}[44,45]$. The peaks at $2250-2400 \mathrm{~cm}^{-1}, 2190 \mathrm{~cm}^{-1}$ and $1650-1810 \mathrm{~cm}^{-1}$ are related to $\mathrm{CO}_{2}, \mathrm{CO}$, and carbonyl compound, respectively. The peak at $915 \mathrm{~cm}^{-1}$ corresponds to the bending vibration of the $\mathrm{NH}_{3}$, and peaks at $1320-1550 \mathrm{~cm}^{-1}$ refer to the stretching vibration of $\mathrm{NO}_{\mathrm{x}}$ (such as $\mathrm{N}_{2} \mathrm{O}, \mathrm{NO}$ and $\mathrm{NO}_{2}$ ) [46], indicating WPU combustion has two main stages: Before the combustion, the WPU decomposed to give flammable gases such as hydrocarbon and carbonyl compounds. With the increase of temperature, a large amount of combustible gas was ignited and the WPU began to burn violently. The FT-IR spectra of the BP/BN/WPU sample (Figure 7d) show a significant enhancement at 1290, 1130 and $1080 \mathrm{~cm}^{-1}$ compared to WPU, which could be explained by the $\mathrm{P}=\mathrm{O}, \mathrm{PO}_{2}-$ and $\mathrm{P}-\mathrm{O}$ groups $[47,48]$. The presence of phosphorus-containing gas should be attributed to the formation of phosphorus-containing radicals from the decomposition of $\mathrm{BP}$, which demonstrates the significant role of BP in the gas-phase flame retardancy. 


\subsubsection{Synergistic Flame-Retardant Mechanisms}

Based on the above flame-retardant performances and analyses, a possible flame retardant mechanism is proposed in Figure 8. At high temperature or in a real fire scenario, BP starts to decompose at about $240{ }^{\circ} \mathrm{C}$. When the temperature reaches $420^{\circ} \mathrm{C}$ or higher, most of the $\mathrm{BP}$ begins to enter the gas phase. The BP nanosheets work in both of the gaseous and condense phases for fire restriction. On the one hand, most of the BP will form radicals in the gas phase by absorbing surrounding oxygen and hydrogen atoms, which react with the pyrolytic radicals of the matrix polymers to inhibit the chain reaction. At the same time, the liberated incombustible gases will dilute the combustible gases and reduce their contact with oxygen. On the other hand, the residual BP will capture the oxygen in the polymers and transform it into phosphoric anhydride, which will promote the formation of a char layer and prevent the release of carbon-containing gas. BN nanosheets mainly remain in the condensed phase, synergistically catalyze carbon, and build a nano-barrier formation with black phosphorus due to the fact that they have good thermo-stability and a peculiar spatial three-dimensional network structure. Therefore, the high efficiency flame retardant performance of $\mathrm{BP} / \mathrm{BN}$ can be attributed to the synergy effects of the gas phase mechanism of black phosphorus and the condensation phase mechanism of boron nitride during the combustion process.

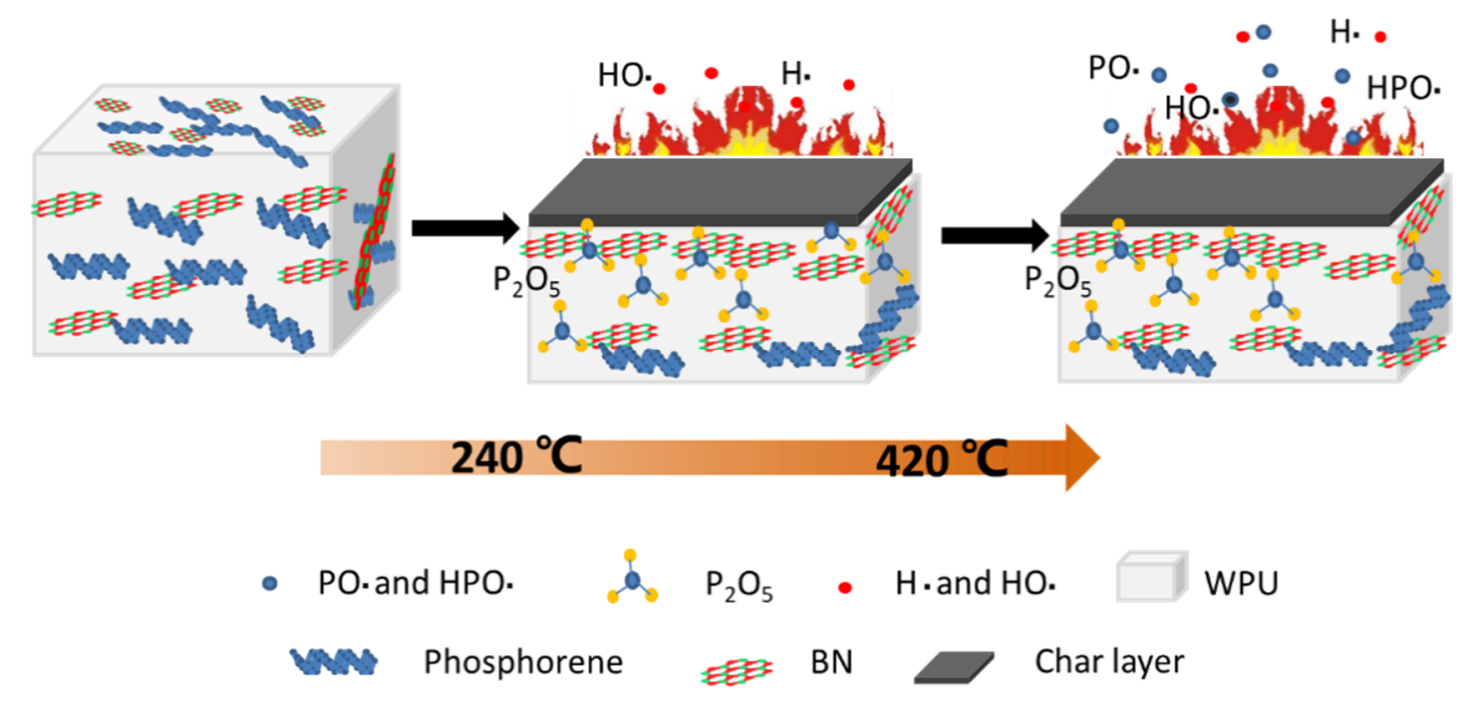

Figure 8. Schematic illustration of the flame-retardant mechanism.

\section{Conclusions}

BP and BN nanosheets were used as a flame retardant for WPU. The SEM and mapping results indicated that the BP and BN nanosheets were distributed uniformly in the matrix WPU. The flame-retardant tests demonstrated that the PHRR of WPU decreases by $50.94 \%$ and the THR decrease by $23.92 \%$ at a BP/BN content of only $0.4 \mathrm{wt} \%$. The LOI of the BP/BN/WPU composite increased from $21.7 \%$ to $33.8 \%$, compared with pure WPU. The residue of BP/BN/WPU after the CC test was denser and approximately 10 times more than the residue of pure WPU, according to TG, SEM, XPS, TG-IR analysis of WPU during the combustion process. Efficient flame retardancy is due to the synergistic effects of BP and BN. To conclude, BP/BN nanosheets can provide a good flame retardant effect with very low addition amount, and have a good application prospect in the field of flame retardancy.

Author Contributions: Conceptualization: X.R., Y.M., P.L., and S.Y.; formal analysis: X.R.; investigation, S.Y. and X.R.; project administration: S.Y.; resources: Y.M.; supervision: Y.M.; writing一original draft: S.Y. and X.R.; writing-review and editing: Y.Z. and P.L. All authors have read and agreed to the published version of the manuscript. 
Funding: This work was supported by the Cultivation Fund for Yunling (No. 10978195, Yunnan, China), the Higher Educational Key Laboratory for Phosphorus Chemical Engineering of Yunnan Province (No. 14058501, Yunnan, China), Yunnan Provincial Key Laboratory of Energy Saving in Phosphorus Chemical Engineering and New Phosphorus Materials (No. 20190002, Yunnan, China), Natural Science Foundation of China (No. 21968012).

Conflicts of Interest: The authors declare no conflict of interest.

\section{References}

1. Laoutid, F.; Bonnaud, L.; Alexandre, M.; Lopez-Cuesta, J.M.; Dubois, P. New prospects in flame retardant polymer materials: From fundamentals to nanocomposites. Mater. Sci. Eng. R Rep. 2009, 63, 100-125. [CrossRef]

2. Chattopadhyay, D.K.; Webster, D.C. Thermal stability and flame retardancy of polyurethanes. Prog. Polym. Sci. 2009, 34, 1068-1133. [CrossRef]

3. Chattopadhyay, D.K.; Raju, K.V.S.N. Structural engineering of polyurethane coatings for high performance applications. Prog. Polym. Sci. 2007, 32, 352-418. [CrossRef]

4. $\quad$ Engels, H.W.; Pirkl, H.G.; Albers, R.; Albach, R.W.; Krause, J.; Hoffmann, A.; Casselmann, H.; Dormish, J. Polyurethanes: Versatile materials and sustainable problem solvers for todays challenges. Angew. Chem. 2013, 52, 9422-9441. [CrossRef]

5. de Wit, C.A. An overview of brominated flame retardants in the environment. Chemosphere 2002, 46, 583-624. [CrossRef]

6. Alaee, M.; Arias, P.; Sjodin, A.; Bergman, A. An overview of commercially used brominated flame retardants, their applications, their use patterns in different countries/regions and possible modes of release. Environ. Int. 2003, 29, 683-689. [CrossRef]

7. Birnbaum, L.S.; Staskal, D.F. Brominated flame retardants: Cause for concern? Environ. Health Perspect. 2004, 112, 9-17. [CrossRef]

8. Tabatabaee, F.; Khorasani, M.; Ebrahimi, M.; Gonzalez, A.; Irusta, L.; Sardon, H. Synthesis and comprehensive study on industrially relevant flame retardant waterborne polyurethanes based on phosphorus chemistry. Prog. Org. Coat. 2019, 131, 397-406. [CrossRef]

9. Yan, Y.; Liang, B. Synthesis of phosphorus-nitrogen flame retardant and its application in epoxy resin. Fine Chem. 2019, 36, 316-321.

10. Lu, S.Y.; Hamerton, I. Recent developments in the chemistry of halogen-free flame retardant polymers. Prog. Polym. Sci. 2002, 27, 1661-1712. [CrossRef]

11. Zhang, S.; Horrocks, A.R. A review of flame retardant polypropylene fibres. Prog. Polym. Sci. 2003, 28, 1517-1538. [CrossRef]

12. van der Veen, I.; de Boer, J. Phosphorus flame retardants: Properties, production, environmental occurrence, toxicity and analysis. Chemosphere 2012, 88, 1119-1153. [CrossRef] [PubMed]

13. Liu, Y.; Wang, Q. Melamine cyanurate-microencapsulated red phosphorus flame retardant unreinforced and glass fiber reinforced polyamide 66. Polym. Degrad. Stabil. 2006, 91, 3103-3109. [CrossRef]

14. Wang, B.B.; Sheng, H.B.; Shi, Y.Q.; Hu, W.Z.; Hong, N.N.; Zeng, W.R.; Ge, H.; Yu, X.J.; Song, L.; Hu, Y. Recent advances for microencapsulation of flame retardant. Polym. Degrad. Stabil. 2015, 113, 96-109. [CrossRef]

15. Liu, H.; Neal, A.T.; Zhu, Z.; Luo, Z.; Xu, X.F.; Tomanek, D.; Ye, P.D. Phosphorene: An unexplored 2d semiconductor with a high hole mobility. ACS Nano 2014, 8, 4033-4041. [CrossRef]

16. Li, L.; Yu, Y.; Ye, G.J.; Ge, Q.; Ou, X.; Wu, H.; Feng, D.; Chen, X.H.; Zhang, Y. Black phosphorus field-effect transistors. Nat. Nanotechnol. 2014, 9, 372-377. [CrossRef]

17. Qiao, J.; Kong, X.; Hu, Z.-X.; Yang, F.; Ji, W. High-mobility transport anisotropy and linear dichroism in few-layer black phosphorus. Nat. Commun. 2014, 5, 1-7. [CrossRef]

18. Qiu, S.L.; Zhou, Y.F.; Zhou, X.; Zhang, T.; Wang, C.Y.; Yuen, R.K.K.; Hu, W.Z.; Hu, Y. Air-stable polyphosphazene-functionalized few-layer black phosphorene for flame retardancy of epoxy resins. Small 2019, 15, 13. [CrossRef]

19. Qu, Z.; Wu, K.; Jiao, E.; Chen, W.; Hu, Z.; Xu, C.; Shi, J.; Wang, S.; Tan, Z. Surface functionalization of few-layer black phosphorene and its flame retardancy in epoxy resin. Chem. Eng. J. 2020, 328, 122991. [CrossRef] 
20. Ren, X.; Mei, Y.; Lian, P.; Xie, D.; Deng, W.; Wen, Y.; Luo, Y. Fabrication and application of black phosphorene/graphene composite material as a flame retardant. Polymers 2019, 11, 193. [CrossRef]

21. Ren, X.; Mei, Y.; Lian, P.; Xie, D.; Yang, Y.; Wang, Y.; Wang, Z. A novel application of phosphorene as a flame retardant. Polymers 2018, 10, 227. [CrossRef]

22. Zou, B.; Qiu, S.; Ren, X.; Zhou, Y.; Zhou, F.; Xu, Z.; Zhao, Z.; Song, L.; Hu, Y.; Gong, X. Combination of black phosphorus nanosheets and monts via phosphoruscarbon bonds for reducing the flammability of air stable epoxy resin nanocomposites. J. Hazard. Mater. 2020, 383, 121069. [CrossRef] [PubMed]

23. Qiu, S.L.; Hou, Y.B.; Xing, W.Y.; Ma, C.; Zhou, X.; Liu, L.X.; Kan, Y.C.; Yuen, R.K.K.; Hu, Y. Self-assembled supermolecular aggregate supported on boron nitride nanoplatelets for flame retardant and friction application. Chem. Eng. J. 2018, 349, 223-234. [CrossRef]

24. Zhang, Q.R.; Li, Z.W.; Li, X.H.; Yu, L.G.; Zhang, Z.J.; Wu, Z.S. Zinc ferrite nanoparticle decorated boron nitride nanosheet: Preparation, magnetic field arrangement, and flame retardancy. Chem. Eng. J. 2019, 356, 680-692. [CrossRef]

25. Feng, Y.Z.; Han, G.J.; Wang, B.; Zhou, X.P.; Ma, J.M.; Ye, Y.S.; Liu, C.T.; Xie, X.L. Multiple synergistic effects of graphene-based hybrid and hexagonal born nitride in enhancing thermal conductivity and flame retardancy of epoxy. Chem. Eng. J. 2020, 379, 13. [CrossRef]

26. Wu, J.X.; Mao, N.N.; Xie, L.M.; Xu, H.; Zhang, J. Identifying the crystalline orientation of black phosphorus using angle-resolved polarized raman spectroscopy. Angew. Chem. Int. Ed. 2015, 54, 2366-2369. [CrossRef]

27. Favron, A.; Gaufres, E.; Fossard, F.; Phaneuf-L'Heureux, A.L.; Tang, N.Y.W.; Levesque, P.L.; Loiseau, A.; Leonelli, R.; Francoeur, S.; Martel, R. Photooxidation and quantum confinement effects in exfoliated black phosphorus. Nat. Mater. 2015, 14, 826-832. [CrossRef]

28. Zhang, S.; Yang, J.; Xu, R.J.; Wang, F.; Li, W.F.; Ghufran, M.; Zhang, Y.W.; Yu, Z.F.; Zhang, G.; Qin, Q.H.; et al. Extraordinary photoluminescence and strong temperature/angle-dependent raman responses in few-layer phosphorene. ACS Nano 2014, 8, 9590-9596. [CrossRef] [PubMed]

29. Yu, X.X.; Cai, R.R.; Jiao, J.L.; Fan, Y.L.; Gao, Q.; Li, J.W.; Pan, N.; Wu, M.Z.; Wang, X.P. Enhanced thermal stability of boron nitride-coated au nanoparticles for surface enhanced raman spectroscopy. J. Alloys Compd. 2018, 730, 487-492. [CrossRef]

30. Chen, L.; Zhou, G.M.; Liu, Z.B.; Ma, X.M.; Chen, J.; Zhang, Z.Y.; Ma, X.L.; Li, F.; Cheng, H.M.; Ren, W.C. Scalable clean exfoliation of high-quality few-layer black phosphorus for a flexible lithium ion battery. Adv. Mater. 2016, 28, 510-517. [CrossRef]

31. Zhao, M.; Qian, H.L.; Niu, X.Y.; Wang, W.; Guan, L.; Sha, J.; Wang, Y.W. Growth mechanism and enhanced yield of black phosphorus microribbons. Cryst. Growth Des. 2016, 16, 1096-1103. [CrossRef]

32. Yu, B.; Xing, W.; Guo, W.; Qiu, S.; Wang, X.; Lo, S.; Hu, Y. Thermal exfoliation of hexagonal boron nitride for effective enhancements on thermal stability, flame retardancy and smoke suppression of epoxy resin nanocomposites via sol-gel process. J. Mater. Chem. A 2016, 4, 7330-7340. [CrossRef]

33. Zhou, F.; Zhang, T.; Zou, B.; Hu, W.; Wang, B.; Zhan, J.; Ma, C.; Hu, Y. Synthesis of a novel liquid phosphorus-containing flame retardant for flexible polyurethane foam: Combustion behaviors and thermal properties. Polym. Degrad. Stabil. 2020, 171, 109029. [CrossRef]

34. Rao, W.-H.; Liao, W.; Wang, H.; Zhao, H.-B.; Wang, Y.-Z. Flame-retardant and smoke-suppressant flexible polyurethane foams based on reactive phosphorus-containing polyol and expandable graphite. J. Hazard. Mater. 2018, 360, 651-660. [CrossRef]

35. Lewin, M. Synergistic and catalytic effects in flame retardancy of polymeric materials-An overview. J. Fire Sci. 1999, 17, 3-19. [CrossRef]

36. Lewin, M. Synergism and catalysis in flame retardancy of polymers. Polym. Adv. Technol. 2001, 12, $215-222$. [CrossRef]

37. Pecht, M.; Deng, Y.L. Electronic device encapsulation using red phosphorus flame retardants. Microelectron. Reliab. 2006, 46, 53-62. [CrossRef]

38. Cai, W.; Guo, W.W.; Pan, Y.; Wang, J.L.; Mu, X.W.; Feng, X.M.; Yuan, B.H.; Wang, B.B.; Hu, Y. Polydopamine-bridged synthesis of ternary h-BN@PDA@SNO2 as nanoenhancers for flame retardant and smoke suppression of epoxy composites. Compos. Pt. A Appl. Sci. Manuf. 2018, 111, 94-105. [CrossRef]

39. Qu, T.; Yang, N.; Hou, J.; Li, G.; Yao, Y.; Zhang, Q.; He, L.; Wu, D.; Qu, X. Flame retarding epoxy composites with poly(phosphazene-co-bisphenol a)-coated boron nitride to improve thermal conductivity and thermal stability. RSC Adv. 2017, 7, 6140-6151. [CrossRef] 
40. Dong, W.; Xiaowei, M.; Wei, C.; Lei, S. Constructing phosphorus, nitrogen, silicon-co-contained boron nitride nano-sheets to reinforce flame retardant properties of unsaturated polyester resin. Compos. Part A Appl. Sci. Manuf. 2018, 109, 546-554.

41. Ryder, C.R.; Wood, J.D.; Wells, S.A.; Yang, Y.; Jariwala, D.; Marks, T.J.; Schatz, G.C.; Hersam, M.C. Covalent functionalization and passivation of exfoliated black phosphorus via aryl diazonium chemistry. Nat. Chem. 2016, 8, 597-602. [CrossRef] [PubMed]

42. Kuo, P.L.; Chang, J.M.; Wang, T.L. Flame-retarding materials-I. Syntheses and flame-retarding property of alkylphosphate-type polyols and corresponding polyurethanes. J. Appl. Polym. Sci. 1998, 69, 1635-1643. [CrossRef]

43. Horold, S. Phosphorus flame retardants in thermoset resins. Polym. Degrad. Stabil. 1999, 64, 427-431. [CrossRef]

44. Hedrick, S.A.; Chuang, S.S.C. Temperature programmed decomposition of polypropylene: In situ ftir coupled with mass spectroscopy study. Thermochim. Acta 1998, 315, 159-168. [CrossRef]

45. Yu, B.; Wang, X.; Qian, X.D.; Xing, W.Y.; Yang, H.Y.; Ma, L.Y.; Lin, Y.; Jiang, S.H.; Song, L.; Hu, Y.; et al. Functionalized graphene oxide/phosphoramide oligomer hybrids flame retardant prepared via in situ polymerization for improving the fire safety of polypropylene. RSC Adv. 2014, 4, 31782-31794. [CrossRef]

46. Zhang, P.K.; He, Y.Z.; Tian, S.Q.; Fan, H.J.; Chen, Y.; Yan, J. Flame retardancy, mechanical, and thermal properties of waterborne polyurethane conjugated with a novel phosphorous-nitrogen intumescent flame retardant. Polym. Compos. 2017, 38, 452-462. [CrossRef]

47. Yuan, B.H.; Fan, A.; Yang, M.; Chen, X.F.; Hu, Y.; Bao, C.L.; Jiang, S.H.; Niu, Y.; Zhang, Y.; He, S.; et al. The effects of graphene on the flammability and fire behavior of intumescent flame retardant polypropylene composites at different flame scenarios. Polym. Degrad. Stabil. 2017, 143, 42-56. [CrossRef]

48. Zhou, S.; Song, L.; Wang, Z.Z.; Hu, Y.; Xing, W.Y. Flame retardation and char formation mechanism of intumescent flame retarded polypropylene composites containing melamine phosphate and pentaerythritol phosphate. Polym. Degrad. Stabil. 2008, 93, 1799-1806. [CrossRef]

(C) 2020 by the authors. Licensee MDPI, Basel, Switzerland. This article is an open access article distributed under the terms and conditions of the Creative Commons Attribution (CC BY) license (http://creativecommons.org/licenses/by/4.0/). 